\title{
Br-319: a rodovia Manaus-Porto Velho e o impacto potencial de conectar o arco de desmatamento à Amazônia central
}

Philip M. Fearnside - Doutor em Ciências Biológicas pela University of Michigan - Ann Arbor e pesquisador titular do Instituto Nacional de Pesquisas da Amazônia (INPA).

Paulo Maurício Lima de Alencastro Graça - Doutor em Sensoriamento Remoto pelo Instituto Nacional de Pesquisas Espaciais e pesquisador titular do Instituto Nacional de Pesquisas da Amazônia - INPA

\section{Resumo}

A Rodovia BR-319 unia Manaus (Amazonas) e Porto Velho (Rondônia) até ficar intransitável em 1988. O governo agora propõe a reconstrução e pavimentação, que facilitaria a migração do "Arco de Desmatamento" para novas fronteiras ao norte. O propósito da rodovia, que é transporte da produção das fábricas da Zona Franca de Manaus para São Paulo, seria mais bem atendido enviando os contêineres para Santos em navios. A falta de uma ligação terrestre atualmente representa uma barreira significante à migração para Amazônia central e do norte. O discurso relativo à reconstrução da rodovia sistematicamente superestima os benefícios da rodovia e subestima seus impactos, particularmente o efeito de facilitar migração do "Arco de Desmatamento" da parte sul da região amazônica para novas e mais distantes fronteiras ao norte. Para atenuar estes impactos potenciais seria necessária uma série de mudanças fundamentais antes de pavimentar a rodovia. Organizar a ocupação amazônica, de tal modo que a construção e melhoria de estradas deixem de conduzir inexoravelmente ao desmatamento explosivo e descontrolado, deveria ser uma condição prévia para a aprovação da BR-319 e outras estradas projetadas, para quais são esperados grandes impactos. Estes projetos quando conduzidos de maneira adequada poderiam prover o ímpeto necessário para deixar para trás o costume de apropriação de terras públicas, tanto por pequenos invasores como por grileiros (grandes reivindicadores ilegais de terra). Retardar a reconstrução desta rodovia seria aconselhável até que mudanças apropriadas pudessem ser efetuadas.

\section{Palavras-chave}

Amazônia, BR-319, Desmatamento, Rodovias, Manaus, Porto Velho, Estradas.

\begin{abstract}
Brazil's BR-319 Highway linked Manaus, in the state of Amazonas, to Porto Velho, Rondônia, until it became impassable in 1988. Now it is proposed for reconstruction and paving, which would facilitate migration from the "Arc of Deforestation" in the southern part of the Amazon region to new frontiers farther north. The purpose of the highway, which is to facilitate transport to São Paulo of products from factories in the Manaus Free Trade Zone, would be better served by sending the containers by ship to the port of Santos. The lack of a land connection to Manaus currently represents a significant barrier to migration to central and northern Amazonia. Discourse regarding the highway systematically overestimates the highway's benefits and underestimates its impacts. A variety of changes would be needed prior to paving the highway if these potential impacts are to be attenuated. Organizing Amazonian occupation in such a way that road construction and improvement ceases to lead to explosive and uncontrolled deforestation should be a prerequisite for approval of the BR-319 and other road projects for which major impacts are expected. These projects could provide the impetus that is needed to achieve the transition away from appropriation of public land by both small squatters and by grileiros (largescale illegal claimants). A delay in reconstructing the highway is advisable until appropriate changes can be effected.
\end{abstract}

\section{Keywords}

Amazonia, BR-319, Brazil, Deforestation, Highways, Manaus, Porto Velho, Roads. 


\section{I) A RODOVIA BR-319}

\section{A) História da Rodovia}

Em 1970 a ditadura militar brasileira iniciou a construção da rodovia Transamazônica, dividindo ao meio a região amazônica de leste para oeste. Ao mesmo tempo, uma vasta rede de rodovias adicionais foi anunciada. A rede de estradas planejadas excedeu em muito as capacidades financeiras do governo, mesmo no período denominado a época do "milagre econômico". A enxurrada de estradas planejadas também excedeu em muito aquilo que seria justificado pelos benefícios econômicos da melhoria de transporte, porque o programa de construção de estradas estava, em parte, incentivado por questões de controle territorial em lugar de questões econômicas. Em 1971, um Decreto-Lei (No. 1.164) deu o controle ao governo federal todas as terras localizadas até $100 \mathrm{~km}$ das rodovias planejadas, até mesmo se a "rodovia" fosse nada mais que uma linha riscada no mapa. $\mathrm{O}$ anúncio da rede de estradas resultou em uma vasta área, somando 2,2 milhões de $\mathrm{km}^{2}$ (quase a metade da Amazônia Legal) sendo transferida do controle estadual ao federal (BRASIL, PIN, 1972). Este foi revogado em 1987 (Decreto-Lei No. 2.375), e qualquer terra dentro de $100 \mathrm{~km}$ de uma rodovia que não tivesse ainda sido alocada a um propósito específico se tornou "terra devoluta" sob controle estadual. Isto afetou uma parte significativa das terras ao longo da BR-319, diferente do caso de outras rodovias, tais como a rodovia Transamazônica e a BR-163, onde as terras nesta faixa foram reivindicadas por órgãos federais.

A rodovia BR-319 possui uma de extensão $877 \mathrm{~km}$ de norte ao sul de Manaus a Porto Velho (Figura 1) e foi construída em 1972 (680 km) e 1973 (197 $\mathrm{km})$. A política governamental requereu na época que todas as rodovias fossem primeiramente construídas como estradas sem pavimento, e apenas seriam pavimentadas depois de decorrido um período de anos e se justificado pelo tráfego na estrada. No caso da BR-319, porém, foi aberta uma exceção especial, e a rodovia foi pavimentada imediatamente na hora da construção. A pressa era tanta que a estrada foi construída na estação chuvosa com a extraordinária prática de proteger o asfalto fresco com lonas de plástico. 


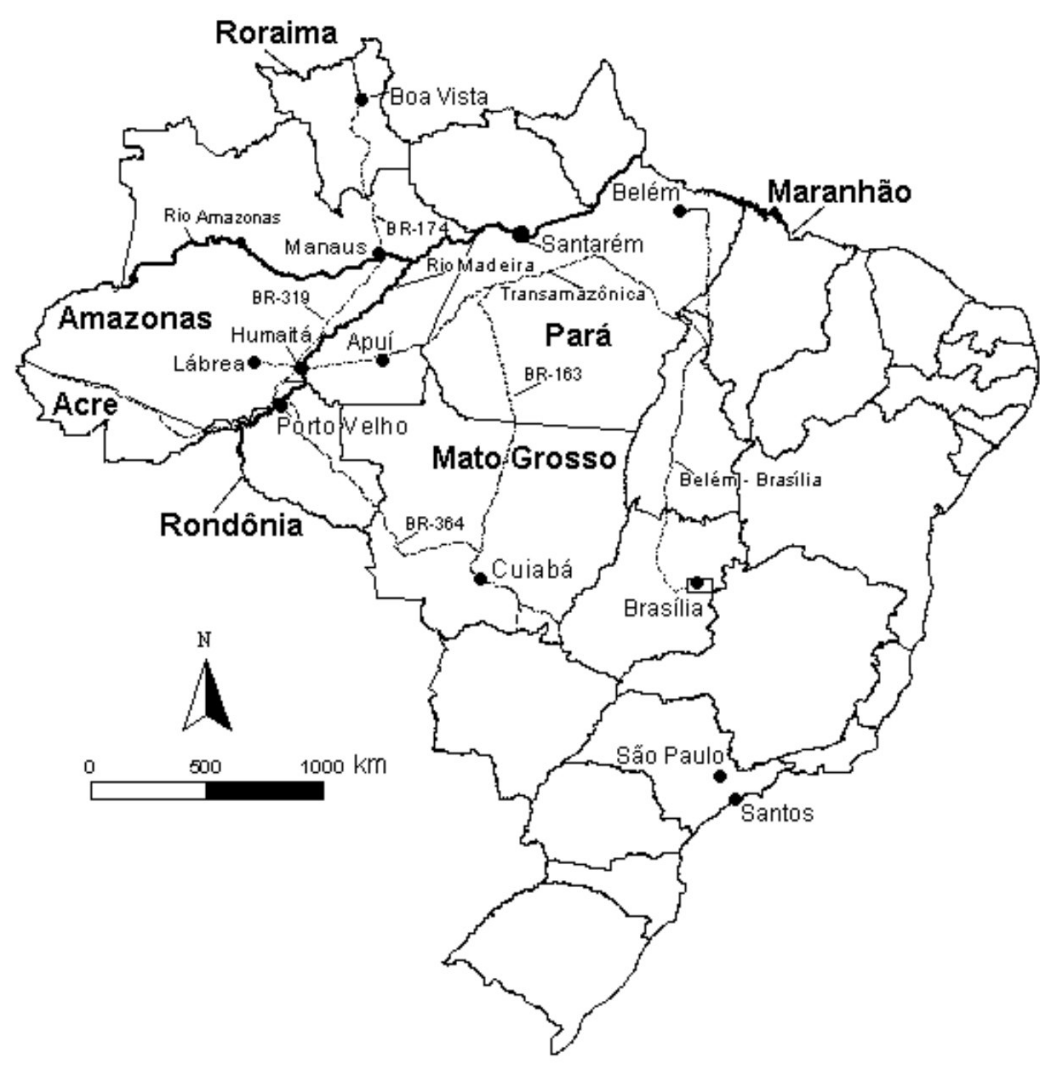

Figura 1: Brasil com locais mencionados no texto.

A alta prioridade dada à pavimentação inicial da rodovia é explicada melhor como parte de um pacote informal de obras públicas e programas federais que foram concedidos ao Estado do Amazonas como um tipo de compensação para os investimentos federais mais pesados no Estado de Pará (por exemplo, MAHAR, 1976, p. 360). A sede da Superintendência do Desenvolvimento da Amazônia (SUDAM) foi estabelecida em Belém, e a grande maioria dos projetos pecuários e outros financiados pela agência estavam localizados no Pará. O Estado do Pará adquiriu também a maior parte da rodovia Transamazônica, incluindo todas as suas áreas de colonização, além da construção da rodovia BR-163 e a pavimentação da rodovia Belém-Brasília (BR-010), seguida logo após pela hidrelétrica de Tucuruí. O Amazonas é um rival tradicional do Pará, e ainda celebra como feriado estadual o dia 5 de setembro, o aniversário da sua independência da autoridade de Belém em 1850. Adicionalmente, o Estado do Amazonas recebeu do governo federal 
a Zona Franca de Manaus (SUFRAMA), a hidrelétrica de Balbina e as rodovias BR-174 e BR-319.

Nos anos 1970, a BR-319 teve pouco tráfego, já que a produção industrial de Manaus foi exportada de forma mais barata por meio de navios, e até via aérea. Rondônia ainda era o destino da maioria dos migrantes do Paraná e de outras áreas fontes que seguiram a rodovia BR-364 (Cuiabá-Porto Velho). Até que Rondônia estivesse repleta e transbordando de migrantes, a BR-319 se degradou a ponto que as condições de trafegabilidade inibiram a migração adicional ao norte. Porém, até que o serviço de transporte por ônibus de Porto Velho para Manaus estivesse suspenso em 1988, muitos migrantes seguiram rumo a Manaus e especialmente a Roraima para afetar significativamente o seu crescimento. As más condições da BR-319 fizeram com que fosse mais fácil para os migrantes que deixavam Rondônia irem para o Acre ou para a parte sul do Estado do Amazonas do que para Manaus ou para Roraima. A alternativa ao transporte rodoviário era uma viagem de barco de quatro dias de Porto Velho para Manaus, o que representou uma barreira significante para os paranaenses, não acostumados à navegação, que constituíam a maior parte da população de migrantes de Rondônia. A camada fina de asfalto na BR-319 se tornou uma série quase contínua de buracos que são, ambos, mais difícil de consertar e mais danoso aos veículos do que seria o caso de uma estrada sem pavimento. Muito da rota teve que ser desviado para trilhas temporárias ao lado da estrada, mais do que o próprio leito da rodovia. O trecho da estrada de Porto Velho até Humaitá permaneceu trafegável desde que a rodovia foi construída, e os primeiros $200 \mathrm{~km}$ ao norte de Humaitá foi colonizado por pequenos agricultores em lotes de 100 ha distribuídos pelo Instituto Nacional de Colonização e Reforma Agrária (INCRA). A maioria destes lotes já mudou de mãos uma ou mais vezes até agora, e está consolidada em pequenas fazendas ("fazendolas") de 500 ha ou mais. A rodovia permaneceu pelo menos marginalmente transitável nos primeiros $100 \mathrm{~km}$, e em grau menor nos $100 \mathrm{~km}$ seguintes.

Em 2001, os primeiros $58 \mathrm{~km}$ da BR-319 depois do entroncamento com a rodovia Transamazônica, a $30 \mathrm{~km}$ ao oeste de Humaitá, foram repavimentados, assim como os $100 \mathrm{~km}$ no extremo norte da rodovia, no sentido Manaus-Careiro Castanho. Um trecho de $340 \mathrm{~km}$ no meio da rota permanece intransitável, embora comboios ocasionais de veículos fizessem este percurso no pico da estação seca em alguns anos. A relutância em gastar recursos limitados na reconstrução da BR319 é, indubitavelmente, um resultado combinado da existência de uma via fluvial (hidrovia) no rio Madeira paralela à rodovia, e o custo muito alto de manter uma rodovia em uma região aonde a chuva média anual chega até $2.200 \mathrm{~mm}$. O discurso político na Assembléia Legislativa do Estado do Amazonas focalizou a culpa em 
um suposto complô contra o projeto por donos de barcaças que transportam carga entre Manaus e Porto Velho (AMAZONAS EM TEMPO, 2005a), enquanto o governador do Estado culpou “interesses econômicos poderosos que estão preocupados com o que o Amazonas está alcançando comparado com o resto do País" (AMAZONAS EM TEMPO, 2005b).

\section{B) Planos para Reconstrução}

A reconstrução e a repavimentação da BR-319 foram planejadas e adiadas repetidamente. O projeto foi incluído inicialmente no programa Brasil em Ação, de 1996-1999, mas foi retirado pelo coordenador do programa, José Paulo Silveira (apesar de objeções feitas por políticos do Estado do Amazonas) por causa da baixa justificativa econômica em comparação com as centenas de outros projetos no programa (J.P. SILVEIRA, declaração pública, 1999; BRASIL, PROGRAMA BRASIL EM AÇÃO, 1999). A proposta de pavimentar a rodovia foi incluída subseqüentemente no programa "Avança Brasil" de 2000-2003 (BRASIL, PROGRAMA AVANÇA BRASIL, 1999; CONSÓRCIO BRASILIANA, 1998), mas somente os $158 \mathrm{~km}$ mencionados acima foram pavimentados de fato. No Plano Plurianual 2004-2007, ou "PPA", lançado sob a presidência de Luiz Inácio Lula da Silva (BRASIL, MPOG, 2004), o projeto da BR-319 aparece listado como previsto para “depois de 2007”, significando que não seria construído durante o termo do plano. No entanto, o Ministro dos Transportes, Alfredo Nascimento (ex-prefeito de Manaus) fez do projeto uma alta prioridade, prometendo começar a construção na estação seca de 2005 (BANEGA \& SIMONETTI, 2005). O partido político de Nascimento (Partido Liberal: PL) fez uso extenso das promessas dele sobre a reconstrução da rodovia em anúncios televisivos em Manaus, em preparação para a sua candidatura na próxima eleição para governador, de outubro de 2006. A BR-319 também tem sido proeminente nas preparativas da candidatura do Nascimento para as eleições para governador de outubro de 2010.

A pavimentação da rodovia BR-319 tem grande apelo público em Manaus. Em março de 2005 todos os 24 deputados estaduais do Amazonas assinaram um "manifesto de apoio" pedindo ao Governo Federal pavimentar a rodovia imediatamente (AMAZONAS EM TEMPO, 2005a). Em Manaus a rodovia é vista, geralmente, como um meio mais barato de exportar produtos industriais para o São Paulo e outros grandes mercados no centro sul brasileiro, e como uma rota mais barata para os habitantes da cidade viajar para estas áreas, por exemplo para visitas de família. O fato da estrada facilitar viagens em ambas as direções, conduzindo assim a migração exacerbada para Manaus, praticamente não é mencionado. 


\section{II) IMPACTOS POTENCIAIS}

\section{A) Impactos ao Longo da Rota da Rodovia}

A pavimentação da BR-319 conduziria a transformação da área adjacente da rota da rodovia. Representantes dos setores de construção industrial e civil em Manaus argumentam que, como a rodovia existiu durante muito tempo, a reconstrução e a pavimentação da mesma não teriam praticamente nenhum efeito ambiental porque "o que era para degradar já foi degradado" (ALMEIDA, 2005). Infelizmente, experiências anteriores de construção e melhoria de estradas na Amazônia resultaram em um padrão de desmatamento que se espalha para além das vias de acesso quando estabelecidas, e que se aceleram quando estas são melhoradas (LAURANCE et al., 2001, 2002; NEPSTAD et al., 2000, 2001; SOARES-FILHO et al., 2004).

O fato de ter ocorrido pouco desmatamento desde a época em que a rodovia BR-319 foi aberta inicialmente às vezes é sugerido como indicativo de que esta região sofreria pouco impacto se a estrada fosse reconstruída e repavimentada. A falta de desmatamento ao longo da rota é atribuída por alguns à chuva excessiva que torna a agropecuária menos produtiva (SCHNEIDER et al., 2000) e às desvantagens econômicas da longa distância até os mercados. Porém, as diferenças físicas não são tão grandes entre a metade sul da BR-319 e as áreas que se tornaram os principais focos de desmatamento no Amazonas desde 2002, tais como as áreas entre Humaitá e Lábrea e entre Humaitá e Apuí. A malária é endêmica e debilitante ao longo da rota da rodovia; porém, isto também não pode explicar o avanço modesto do desmatamento, desde a construção original, já que a doença afeta outras áreas com taxas de desmatamento altas.

A agricultura ao norte do trajeto é pouco promissora por causa de solos menos férteis. A porção do norte está ocupada por solos hidromórficos, que são menos desejáveis para agropecuária que o argissolo (podzólico vermelho-amarelo) que ocupa a maior parte dos primeiros $300 \mathrm{~km}$ ao norte de Humaitá (Brasil, Projeto RADAMBRASIL, 1973-1982, vols. 17 \& 18). Há mais solo hidromórfico no lado oeste do que no lado leste da estrada. Apesar de limitações agrícolas, a porção do norte da rodovia tem sido o foco de projetos de assentamento como Panelão e Igarapé Açu, no município de Castanho Careiro. Embora solos inférteis sirvam para desestimular um pouco o desmatamento, a noção de que isto confere uma certa imunidade ao desmatamento é errônea como mostrado através de exemplos freqüentes (e.g., FEARNSIDE, 1986a).

Algumas indicações de aumento potencial de desmatamento ao longo da BR-319 são evidentes. Houve várias aquisições de terra em antecipação à 
pavimentação, com implantação de agricultura intensiva de capital (arroz, seguido por soja). Segundo relatos de moradores locais, uma propriedade a $120 \mathrm{~km}$ e várias áreas a $200 \mathrm{~km}$ ao norte de Humaitá foram compradas por investidores maiores provenientes de Mato Grosso. Porém, em 2005 a rentabilidade agrícola era em um ponto econômico baixo, com quedas significativas nos preços de arroz, soja e carne bovina que causaram perdas para agricultura e pecuária em toda a Amazônia. Preços em mercados globalizados e outros fatores econômicos, incluindo a taxa de câmbio do Real frente ao dólar americano, seguem ciclos e podem ser esperados a voltar para aumentar a pressão por desmatamento em níveis equivalentes ou maiores que os experimentados na última década.

Outro processo que indica um aumento potencial no desmatamento ao longo do eixo da rodovia caso a estrada seja repavimentada é a chegada de migrantes sem-terras. Isto inclui, por exemplo, o estabelecimento de um acampamento de sem-terras no Igarapé Realidade (100 km ao norte de Humaitá: Figura 2). Os migrantes sem terra no acampamento no Igarapé Realidade estão organizados na forma de comunidade (embora não se identificam como pertencendo a quaisquer dos movimentos nacionais de sem-terras, como o Movimento dos Trabalhadores Rurais Sem-Terra, ou MST). Dois ônibus de migrantes foram obrigados a voltar para Rondônia depois de uma confrontação com a polícia, mas aproximadamente 30 famílias permaneceram no acampamento e na área circunvizinha, e, ao longo do período 2005-2008 este acampamento evoluiu para se tornar uma vila e um assentamento. Antigos residentes na área reivindicam as áreas com desmatamentos iniciados em várias partes da área "fundiária" (as terras públicas atrás da faixa de $2 \mathrm{~km}$ dos lotes que foram originalmente distribuídos pelo INCRA ao longo da margem da estrada). Esta área de terra pública já tem vários pretendentes, inclusive os residentes tradicionais da área que se ocupam da colheita de castanha-do-pará (Bertholetia excelsa), e várias reivindicações maiores por donos individuais e empresas, de blocos de lotes ao longo da rodovia. Os residentes ao longo da rodovia acreditam que a propriedade de um lote à margem de estrada confere ao dono o direito a uma área praticamente ilimitada de terra pública que se encontra atrás da área colonizada. Por sua vez, o INCRA diz que os colonos não têm nenhum direito desse tipo (DAVID BENEDITO GONÇALVES, comunicação pessoal, 2005). 


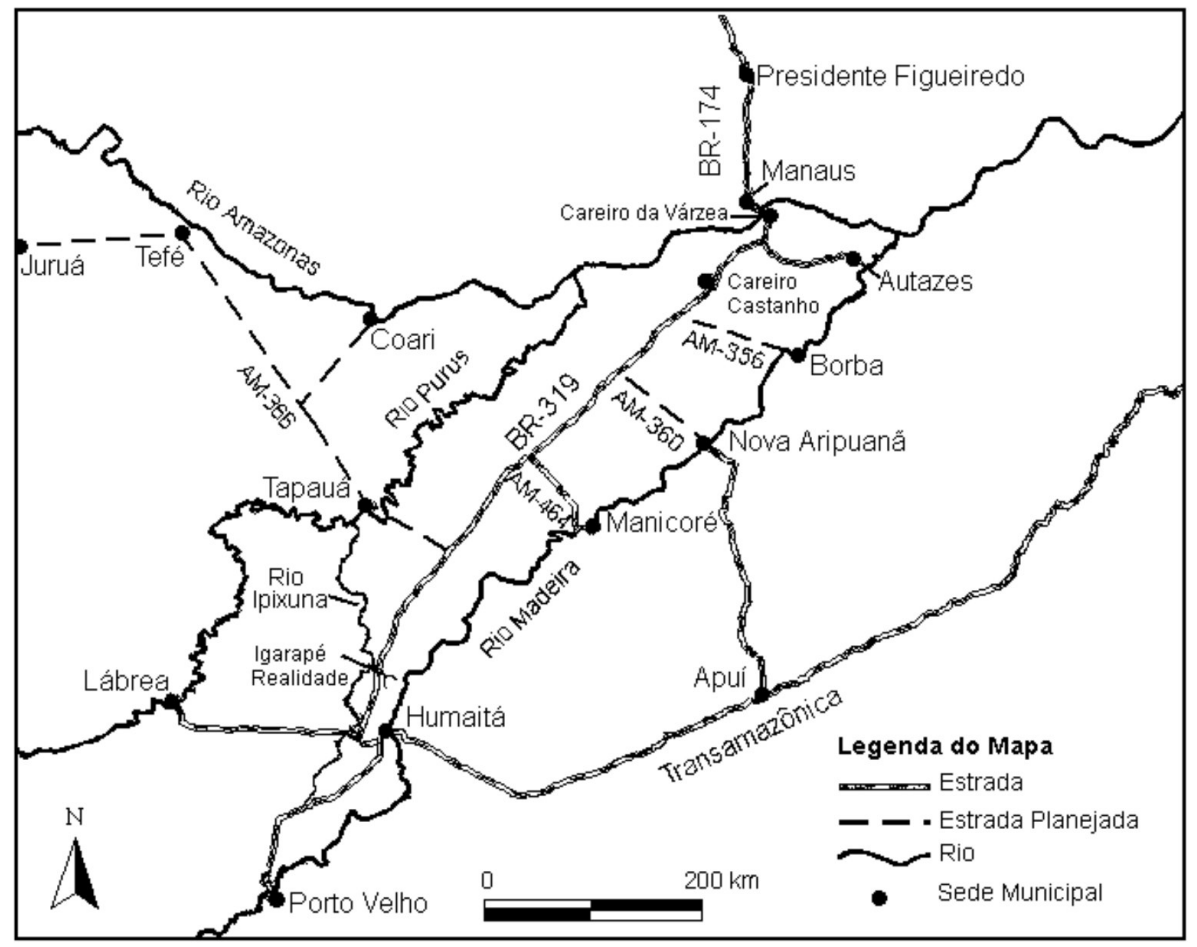

Figura 2: A rodovia BR-319.

Além dos migrantes no Igarapé Realidade, um fluxo de pessoas procurando terra de forma independente apareceu buscando áreas para estabelecer posses. Alguns destes vêm de barco, sendo deixados às margens do rio Madeira para então vagar pela floresta em busca de terra não ocupada. Espera-se que estes agentes individuais de áreas já ocupadas em Rondônia viajem para todos os pontos ao longo da estrada uma vez que o acesso seja melhorado. Atualmente existem linhas de ônibus operando até $200 \mathrm{~km}$ ao norte de Humaitá.

A reivindicação de grandes áreas por grileiros (grandes pretendentes ilegais) tem levado a um padrão de violência no qual pistoleiros são contratados para remover quaisquer pretendentes concorrentes. O delegado do Instituto Nacional de Colonização e Reforma Agrária (INCRA) no Amazonas denunciou a prevalência deste padrão na região (LITAIFF, 2005). A visão do governador estadual de que a BR-319 vai se tornar um "corredor de agricultura familiar" (AMAZONAS EM TEMPO, 2005b) pareceria ser um cenário improvável sem primeiro alcançar o sucesso na implantação de governança na área.

O efeito da BR-319 não é apenas restrito à área diretamente acessada pela rodovia, mas também por uma série de estradas laterais planejadas que conectarão 
a BR-319 a sedes municipais nos rios Madeira e Purus (FEARNSIDE et al., 2009). Estas incluem Manicoré, Borba, Novo Aripuanã e Tapauá. Os planos para as estradas laterais (vicinais) já estão estimulando os políticos locais a resistir à criação de reservas de proteção ambiental perto das rotas propostas. Uma reserva indígena proposta, que limita a estrada planejada AM-465, que dá acesso a Tapauá, é foco de objeções de vereadores de Tapauá que querem as terras abertas por esta estrada lateral sejam destinadas à agricultura (AMAZONAS EM TEMPO, 2005c).

A existência de áreas protegidas de vários tipos pode reduzir significativamente a velocidade do avanço de desmatamento, assim reduzindo a probabilidade de que qualquer determinado hectare sofra uma transformação de floresta para outro uso da terra (FERREIRA et al., 2005). Às vezes um mero rumor de que uma reserva será criada pode desencorajar a invasão. No momento não há quase nenhuma reserva para restringir o desmatamento ao longo da BR-319, embora a intenção de criar tais reservas seja uma preocupação importante entre os fazendeiros e pecuaristas maiores em Humaitá e ao longo da porção ocupada da rodovia. O governo federal já criou uma reserva extrativista (RESEX): Carapanã Grande. O governo estadual planeja a criação da reserva de desenvolvimento sustentável (RDS) rio Amapá. A área ao entorno da BR-319 é de interesse para criação de reservas por ser um interflúvio com diversidade biológica particularmente alta (MARIO COHN-HAFT, comunicação pessoal, 2005).

\section{B) Impactos na Amazônia Central}

Manaus hoje é uma ilha de paz que parece estar fora da Amazônia. Ao norte da cidade está o Distrito Agropecuário da SUFRAMA onde grandes fazendas foram estabelecidas no início da década 1980 com incentivos fiscais generosos e pacotes de financiamento subsidiados pelo governo. Quando o fluxo de fundos do governo encolheu em meados dos anos 1980, a maioria das pastagens foi abandonada. Hoje mais de $80 \%$ da área desmatada está ocupada por vegetação secundária (capoeira). Ainda assim, nenhum migrante sem terra invade a área; não há nenhuma batalha entre os posseiros e pistoleiros, nenhum barraco queimado e nenhuma morte. Se as mesmas fazendas abandonadas fossem magicamente transportadas para o sul do Pará, norte de Mato Grosso ou para Rondônia provavelmente seriam invadidas dentro de algumas semanas, se não de dias!

O cenário calmo em áreas rurais ao redor de Manaus poderia mudar rapidamente com a abertura de uma ligação pavimentada para o "Arco de Desmatamento", área em expansão localizada ao longo das margens sul e leste da floresta amazônica onde atividade de desmatamento está concentrada. As incursões relativamente modestas de migrantes de sem-terras na BR-319 hoje, 
como o acampamento do Igarapé Realidade, não revelam a magnitude do impacto que acontece quando novas fronteiras de migração se tornam disponíveis. O efeito muito mais forte em áreas de fronteira no sul do Pará oferece uma indicação melhor deste potencial (FEARNSIDE, 2001). Estimativas do número de famílias rurais sem terras em todo o Brasil variam de 5 a 10 milhões, excedendo em muito a capacidade da região amazônica até mesmo se a região fosse completamente distribuída em projetos de assentamento (por exemplo, FEARNSIDE, 1985).

Pode-se esperar, também, que Manaus receba um fluxo substancialmente crescente de migrantes urbanos. A migração de áreas rurais para urbanas e de áreas urbanas para urbanas são tendências poderosas na redistribuição da população brasileira (BRASIL, IBGE, 2005; BROWDER \& GODFREY, 1997). O distrito industrial em Manaus, que se beneficia de isenções de impostos, empregou 82,7 mil pessoas em abril de 2005 (BRASIL, SUFRAMA, 2005a); este foi o principal ímã de atração de população para a cidade (população aproximadamente 1,6 milhões em 2005).

Muito da migração para Manaus tem sido de populações ribeirinhas do interior da Amazônia até agora, mas este fluxo poderia ser tolhido pela vinda de novos migrantes do resto do Brasil se o acesso fosse facilitado. O desemprego em Manaus é mais baixo do que em muitas cidades brasileiras, embora a reputação que Manaus desfruta para os níveis altos de emprego não é completamente merecida. Manaus tem 141 empregos formais por mil habitantes; das capitais das unidades federativas brasileiras, um terço tem mais desemprego que Manaus enquanto dois terços têm menos (BRASIL, IBGE, 2005). Porém, Manaus tem a melhor razão entre emprego e população de qualquer cidade importante na região Norte.

Renda per capita fornece outro indicador da atratividade de Manaus como destino à migração. O Estado do Amazonas é muito melhor que os estados circunvizinhos, e tem renda per capita mais alta que qualquer outro estado no Brasil com a exceção do Distrito Federal, Rio de Janeiro, São Paulo, Rio Grande do Sul e Santa Catarina. A renda per capita no Amazonas é até ligeiramente maior do que no Paraná, que é bem conhecido como um estado rico. A renda per capita do Amazonas é mais que o dobro do Pará, e quatro vezes maior do que a do Maranhão (Figura 3). De grande importância para a BR-319 é o fato de o Amazonas ter quase o dobro da renda per capita de Rondônia. 


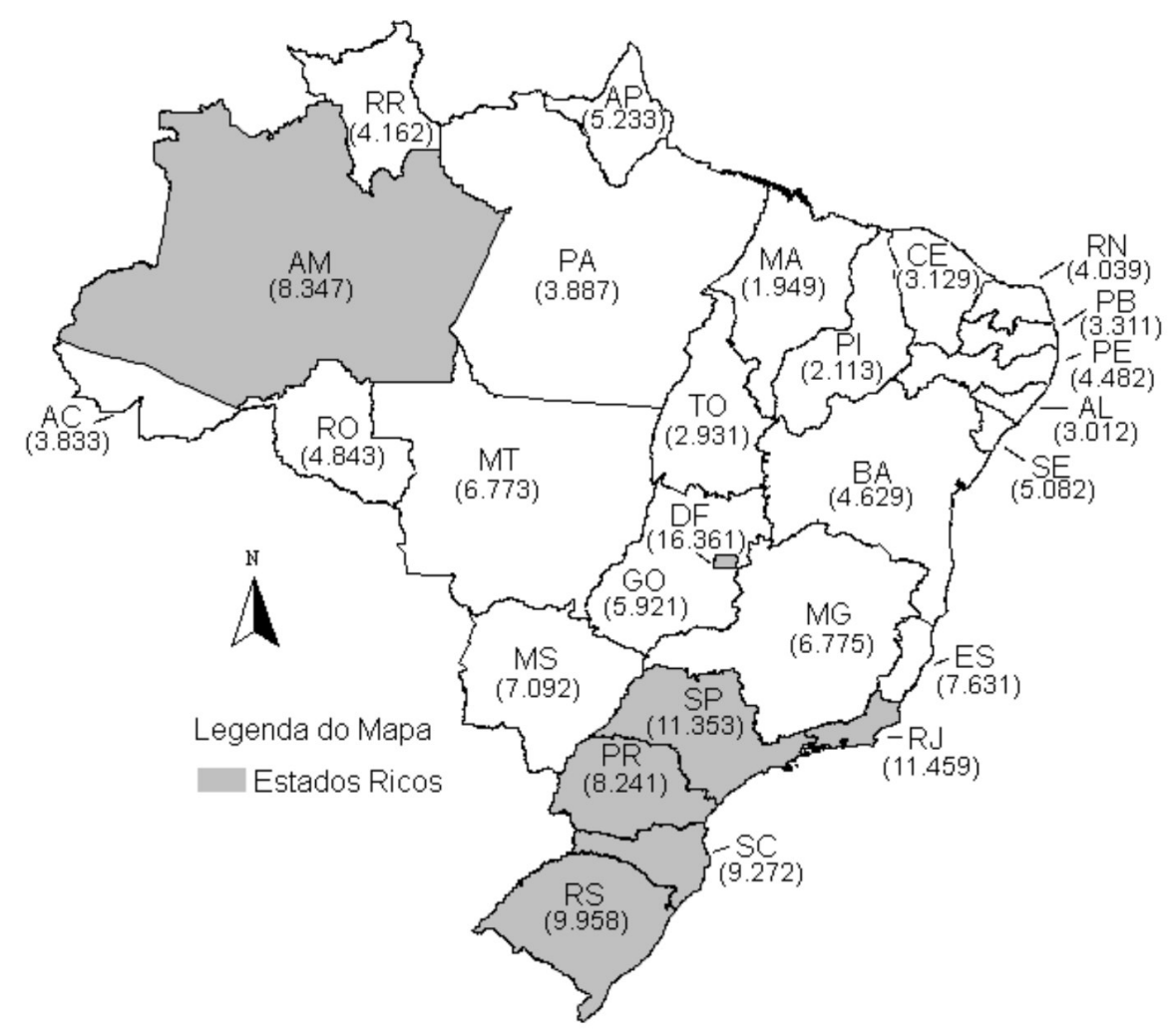

Figura 3: Renda per capita nos estados brasileiros em 2002.

Fonte de dados: IPIB (2005). Valores in Reais em 2002 (US\$1 = R\$2,28). Estados "ricos" têm renda per capita acima de $\mathrm{R} \$ 8$ mil.

Desnecessário dizer que a chegada massiva de migrantes urbanos em Manaus degradaria os serviços sociais já precários e aumentaria os problemas urbanos tais como desemprego, subemprego, invasões urbanas e criminalidade. É de esperar que a taxa de migração de outras partes do Brasil seja proporcional à disparidade em relação a oportunidades de emprego e padrões de vida entre os locais fontes e de destino, conduzindo a uma redução das qualidades atrativas do local de destino até que um equilíbrio seja estabelecido. A magnitude da disparidade que pode ser mantida em equilíbrio depende da fricção, ou resistência, à migração representada por impedimentos como a falta de acesso de estrada para Manaus. Manaus hoje se mantém como uma ilha de riqueza da mesma forma que uma garrafa térmica mantém seu café quente por meio do impedimento da parede da garrafa à passagem de calor. Colocando o mesmo café quente em um bule de ferro, ele se esfria logo. 
Quando os impedimentos à migração forem afastados, o equilíbrio poderia mudar na medida em que a taxa elevada de migração abaixasse as características atraentes da área de destino. Um exemplo é a cidade de Sorriso, em Mato Grosso, que está no centro do "boom" da soja em Mato Grosso: era o assunto de reportagens freqüentes porque o "boom" econômico na área resultou no alcance do Índice de Desenvolvimento Humano (IDH) mais alto do Brasil. Um ano depois, o prefeito da cidade lamentava que a publicidade sobre o IDH resultasse em um excesso de migrantes. Com cinco ônibus lotados de pessoas chegando por dia, o prefeito estava procurando meios para desencorajar a migração que já aumentou a população escolar em 36\% (FOLHA DE SÃO PAULO, 2005).

Criar emprego é uma luta interminável para autoridades a todos os níveis em Manaus, como também é o caso em outros lugares. Esta luta pode facilmente se tornar um trabalho de Sísifo. Assim como o Sísifo da mitologia grega, que foi condenado a rolar eternamente um pedregulho pesado para cima de uma colina em Hades, para que a pedra rolasse de volta ao fundo da colina cada vez que ela se aproximasse ao topo, a luta de Manaus para empregar sua população seria em vão se para cada posto de trabalho criado, três ou quatro migrantes desempregados chegassem à cidade.

\section{C) Impactos em Roraima}

É provável que o potencial à migração crescente em direção a Roraima seja um dos principais impactos em pavimentar a BR-319 (BARNI et al., 2009). Aparte do fluxo de população existente há muito tempo do Maranhão para o Pará, Rondônia se tornou a principal fonte de migração para outros estados amazônicos, os destinos principais são áreas como Apuí (no sul do Amazonas), Acre oriental, e um movimento significante para o noroeste de Mato Grosso (invertendo o fluxo tradicional de Mato Grosso para Rondônia). Roraima também é um destino, embora a dificuldade de transporte entre Rondônia e Manaus contenha a migração no momento nesta rota. No início da década 1980, quando a BR-319 era transitável, uma fração significativa dos migrantes que chegaram a Manaus pela rodovia seguiu diretamente para Roraima pela BR-174, em lugar de se instalar na Amazônia central. Isto é explicado parcialmente pela geoquímica, já que Roraima, situada em parte na formação Boa Vista, possui solos mais jovens e mais férteis do que a área de Manaus. A migração também é explicada em parte pelo encorajamento ativo do governo de Roraima, na distribuição de terras em áreas de assentamento, no fornecimento de transporte subsidiado até mercados e nos outros serviços, e até mesmo programas ativos para transportar migrantes novos ao estado como parte de estratégias de eleição (veja FEARNSIDE \& 
BARBOSA, 1996a). Roraima ganhou uma reputação como um estado onde o nível de governança ambiental é próximo de zero (FEARNSIDE \& BARBOSA, 1996a,b). Uma exceção importante é a barreira ao desmatamento atribuído pela grande extensão de reservas indígenas e unidades de conservação em Roraima (em ambos os casos criados por autoridades federais).

\section{III) BENEFÍCIOS DA RODOVIA}

Os benefícios de pavimentar a BR-319 são, indubitavelmente, menores do que aqueles retratados no discurso político que cerca o assunto. A justificação principal apresentada é a redução de custos de transporte no frete para o centrosul brasileiro, aumentando assim a competitividade de produtos industriais de Manaus nos mercados em São Paulo e em outros centros de população. Porém, os produtos industriais de Manaus, como televisores e motocicletas, não são artigos perecíveis para os quais a diferença de alguns dias em tempo de transporte faria uma diferença significante. Remessa de tal frete por navio para o porto de Santos é muito mais eficiente tanto em termos de uso de energia como em termos de custos de mão-de-obra, quando comparado com a remessa em milhares de caminhões, qualquer que seja a rota rodoviária. É notável que os mesmos argumentos usados como justificativa para a BR-319 estão sendo simultaneamente usados como parte da justificativa para pavimentar a rodovia BR-163 de Santarém à Cuiabá (por exemplo, SIMONETTI, 2005; BRASIL, SUFRAMA, 2005b). O frete atualmente levado de Manaus para Belém em barcaças e transportado em caminhão para São Paulo pela rodovia Belém-Brasília (BR-010) leva 11 dias, e chegaria em 5 dias se transportado em caminhão a partir de Santarém (BRASIL, BNDES, 1998, p. 68). Desnecessário dizer que contabilizando o mesmo frete para justificar a BR-319 implica que este benefício evaporaria para a BR-163. A atual rota multimodal via Porto Velho é mais barato que a rota via Belém, mas só é utilizável durante uma parte do ano porque o rio Madeira não permanece navegável, no seu período de vazante (o nível de água no rio varia em $15 \mathrm{~m}$ ao longo do curso do ano, e a profundidade em Porto Velho é de apenas $2 \mathrm{~m}$ quando a vazão do rio chega ao seu mínimo anual).

A rota de transporte por caminhão de Manaus para São Paulo pela rodovia Belém-Brasília pareceria faltar lógica quando comparada com movimento de frete por cabotagem, ou navios litorais, entre Manaus e Santos. O Banco Nacional do Desenvolvimento Econômico e Social (BNDES), que é responsável em promover o desenvolvimento de infra-estrutura de transporte, estimava que uso dos navios reduziria o custo do frete porta a porta em $50 \%$ quando comparado 
às atuais opções via barcaça e rodovia (BRASIL, BNDES, 1998, p. 102). Porém, conforme constatado pelo BNDES, o "transporte de carga geral por cabotagem é praticamente inexistente” (BRASIL, BNDES, 1998, p. 64). O BNDES (1998, p. 100) estabelece que "o maior impedimento para movimento deste frete por cabotagem está na ineficiência e insegurança dos portos. .... Se taxas e qualidade de serviço estivessem em acordo com normas internacionais, assim tornando a operação regular de cabotagem viável, o frete entre Manaus e a região sudeste cairia em aproximadamente $\mathrm{R} \$ 3$ mil [US $\$ 2,6$ mil na época][por cada contêiner], ou a metade do custo atual". Além de custos portuários, o BNDES também enfatiza preços "abusivos" de serviços auxiliares. Somente as taxas de praticagem no rio Amazonas custavam R $\$ 100$ [US\$86] por contêiner em 1998, em média, ou 3\% do custo total de frete entre Manaus e São Paulo.

A infraestrutura física dos portos foi melhorada sob os programas Brasil em Ação e Avança Brasil. No entanto, parte da insegurança dos portos resulta da dependência de estivadores em Santos para descarregar os navios. O sindicato de estivadores tem fechado este porto estratégico periodicamente durante as últimas décadas, em decorrência de greves sobre assuntos trabalhistas. De fato, acredita-se que o objetivo de quebrar o poder de estrangulamento deste sindicato foi uma das razões para que o governo militar brasileiro lançasse seu programa maciço de construção de rodovias nos anos 1970. O temor a tais eventos não deveria ser usado para justificar a manutenção artificial de alternativas de transportes onerosas e ambientalmente destrutivas, já que esta fonte de incerteza não é maior para cabotagem do que é para quaisquer das exportações principais do Brasil, tais como a soja.

O porto de Manaus é o mais ineficiente do Brasil em termos do número de horas necessárias para carregar e descarregar um navio: 36 horas, ou duas vezes o tempo que leva em Santos (ONO, 2001, p. 43). Além de serem ineficientes, os portos também são caros. Em um relatório pela Confederação Nacional do Transporte, uma "ação necessária" identificada para tornar a cabotagem viável é "reduzir o excedente de mão-de-obra nos portos" (CNT, 2002, p. 148). A modernização reduziu o número de tarefas manuais, assim resultando em trabalhadores em excesso. A Confederação Nacional do Transporte esboça uma estratégia de negociação baseado em ofertas de aposentadoria antecipada para estes trabalhadores. Porém, nós sugeriríamos que no caso de Manaus muito disto pudesse ser desnecessário, já que a necessidade de expansão do porto deveria permitir que os atuais trabalhadores fossem retidos.

O discurso político relativo aos benefícios de transportar a produção industrial de Manaus para São Paulo por caminhão pela BR-163 ou pela BR-319 
pode ter pouca relação ao real desdobramento dos fatos, uma vez que as rodovias sejam pavimentadas. Por exemplo, a pavimentação da rodovia BR-174 em 1997 foi justificada com base de que seriam transportados em caminhão produtos industriais de Manaus para a Venezuela, de onde seriam exportados por navio para o porto de Houston, Texas, E.U.A. (ABDALA, 1996). Isto foi planejado para reduzir em 15 dias o tempo do percurso, comparado com a exportação dos produtos diretamente por navio a partir de Manaus. Depois que a rodovia foi pavimentada, nenhuma frota de caminhões apareceu para tirar proveito desta nova rota de exportação. A maior eficiência econômica de exportar diretamente por navio é evidente, a diferença em custo excede o valor de economizar duas semanas em transporte. Não obstante, o discurso relativo a uma rota de caminhão para a Venezuela serviu seu propósito, ganhando apoio político para pavimentar a rodovia. O aumento de desmatamento em Roraima é um dos custos contínuos da rodovia BR-174.

É provável que o benefício principal da BR-319 seja os benefícios políticos para os que conseguem levar o crédito pela sua reconstrução. Deveria ser notado que a construção seria feita com fundos federais, não com fundos dos contribuintes do Estado do Amazonas. Esta diferença de perspectiva pode ser crucial na percepção de que grandes investimentos valem à pena; a construção da Hidrelétrica de Balbina perto de Manaus é um exemplo claro (FEARNSIDE, 1989a). Outro grupo influente são as empresas de construção e os provedores potenciais de bens e serviços ao esforço de construção. Como qualquer investimento público de grande porte, cujos custos financeiros vêm de contribuintes espalhados por todo o País enquanto que a atividade comercial e os empregos gerados na fase de construção são localizados (por exemplo, em Manaus), pode ser esperado que um lobby de apoio local se desenvolva até mesmo caso o projeto em questão tenha justificativa econômica mínima. Por exemplo, a Hidrelétrica de Balbina é conhecida como um projeto "faraônico" porque, como no caso das pirâmides de Egito antigo, ergueu-se uma estrutura enorme a grande custo com pouco ou nenhum retorno prático (FEARNSIDE, 1989a).

Além do frete industrial que é visto como condutor de aumento de empregos em Manaus, uma fonte importante de apoio à pavimentação da BR-319 está na imaginação de residentes de classe média de Manaus que se visualizam fazendo viagens de férias para o centro-sul brasileiro, embora a maioria das tais viagens provavelmente nunca viesse a acontecer (pelo menos por estrada). Acabar com o "isolamento" de Manaus demonstra ser um lema poderoso, mas raramente é lembrado que se trata de uma moeda com dois lados, o outro sendo a chegada de um fluxo de migrantes para Manaus. 


\section{IV) A BR-319 E O PROCESSO DE TOMADA DE DECISÃO}

O processo de tomada de decisão sobre a reconstrução da BR-319 segue o padrão evidente em outros projetos de infra-estrutura amazônica de subestimar substancialmente os impactos e superestimar os benefícios de obras públicas propostas. O mais notável neste caso é o efeito de não contabilizar o impacto ambiental e social da estrada que é o impacto potencial do fluxo de população para a Amazônia Central e para Roraima. Os impactos de construir o leito rodoviário propriamente dito são mínimos quando comparado aos impactos de alcance mais longo, tais como o fluxo populacional e o aumento da atividade de desmatamento (e.g., FEARNSIDE, 2005).

A necessidade por um repensar dos planos para reconstruir a BR-319 neste momento é sugerida pelos altos custos ambientais e sociais e os benefícios modestos quando visto em uma luz mais realística do que o discurso político atual. Os impactos poderiam ser reduzidos na rodovia se uma decisão em pavimentar fosse adiada por vários anos e se fosse feito bom uso do tempo interveniente. Uma alternativa que o governo do Estado do Amazonas faria bem em explorar é a promoção de um serviço de cabotagem regular entre os portos de Manaus e Santos. O porto de Manaus é capaz de receber navios oceânicos de todos os tamanhos, mas o transporte é focalizado principalmente em mercados externos. Uma resistência a isto pode ser esperada por empresários por questão de interesses financeiros da atual operação de barcaças para Belém e Porto Velho. No entanto, esses mesmos interesses também seriam contra o projeto de reconstrução da BR319. Em 1996, havia 15 empresas transportando carga geral para Belém e oito empresas para Porto Velho (BRASIL, BNDES, 1998, p. 66 \& 79).

O zoneamento ecológico-econômico do Estado do Amazonas, já foi realizado em forma preliminar (ESTADO DO AMAZONAS, 2001), mas precisa ser fortalecido e implementado. Em Roraima foi concluído um zoneamento, mas foi deixado sem implementação porque o órgão ambiental estadual não enviou a proposta de zoneamento à Assembléia Legislativa do estado. Deveria ser enfatizado que a condição prévia necessária para a decisão de pavimentar uma rodovia não é um plano ou um comitê, mas reais mudanças que sejam implantadas de fato antes da aprovação ser concedida. Pressupõe-se que as medidas de mitigação que serão implantadas simultaneamente com pavimentação da rodovia representam uma fórmula para o desastre ambiental, como amplamente mostrado pela história da rodovia BR-364 (FEARNSIDE, 1989b).

A criação de reservas ambientais e a sua implantação (incluindo a contratação de pessoal) ao longo do eixo rodoviário é uma medida importante que precisa, 
não só estar no lugar antes da rodovia ser aberta, mas antes que os efeitos de expectativas de uma futura pavimentação corroam as possibilidades de criar tais áreas. As reservas podem formar barreiras paralelas à rodovia para conter a expansão do desmatamento a partir das margens da estrada. No caso de reservas extrativistas, estas oferecem também a possibilidade de manter a economia atual baseada na colheita de castanha-do-pará, uma atividade que é sacrificada onde o desmatamento avança e onde os residentes locais são substituídos.

A falta de governança é um problema crônico na BR-319, assim como em outros lugares na Amazônia. Ambos a agência ambiental federal (IBAMA: Instituto Brasileiro do Meio Ambiente e dos Recursos Naturais Renováveis) e o órgão estadual (IPAAM: Instituto de Proteção Ambiental do Amazonas) são muito fracos quando comparado aos desafios que eles enfrentam. A execução de regulamentos ambientais é mínima, tanto para os que exigem uma reserva legal de $80 \%$ em cada propriedade situada na parte da Amazônia onde a vegetação original é de floresta, assim como para aqueles regulamentos que exigem as áreas de proteção permanente (APPs) ao longo de cursos de água e em locais acidentados. Uma combinação de sensoriamento remoto, campanhas de campo, e de cooperação íntima entre os órgãos de execução e o sistema judiciário se mostrou eficaz em influenciar o comportamento de desmatamento, a exemplo de Mato Grosso no seu programa de licenciamento e controle de desmatamento de 1999 a 2001, quer dizer, sob um governo estadual prévio (FEARNSIDE, 2003; FEARNSIDE \& BARBOSA, 2003). Estes métodos ainda não têm sido aplicados no Amazonas e nem em Roraima.

Um impedimento básico para uma governança melhor é a falta de um cadastro das terras, que tornaria possível identificar quem possui qualquer determinado pedaço de terra. Isto precisa ser feito sem legalizar as reivindicações tanto de grileiros ou dos pequenos invasores. Embora um cadastro nacional esteja em preparação pelo INCRA, progresso neste projeto de longo prazo ainda não alcançou a área da BR-319. O Instituto de Terras do Amazonas (ITERAM) também ainda não teve sucesso em montar um banco de dados georreferencidado das propriedades nas áreas que o órgão controla.

São necessárias mudanças fundamentais e de longo alcance, além de medidas mais paliativas para conter o desmatamento por meio de zoneamento, criação de reservas e fazer cumprir os regulamentos ambientais. A falta de alternativas de emprego precisa ser endereçada em contextos urbanos e rurais. No contexto rural, fatores que agem para desencorajar a contratação de trabalho incluem o fardo pesado de "custos sociais", tais como a previdência social. O mercado informal (não regulado) de trabalho domina em grande parte do interior amazônico. Abusos 
como a escravidão por dívida são um resultado comum. Este é um resultado lógico da governança fraca que arruína a execução de regulamentos de todos os tipos.

Os tipos de uso de terra escolhidos desencorajam a criação de emprego rural estável. A exploração madeireira é um empregador significante, mas a falta de sustentabilidade deste uso da terra, até mesmo quando executado como parte de planos de manejo aprovados, conduz a um movimento ininterrupto de serrarias e fronteiras de exploração madeireira. O próprio processo de desmatamento emprega uma mão-de-obra significante na Amazônia, mas necessariamente é um fenômeno efêmero em qualquer determinado local (e, em longo prazo, na região como um todo). O uso da terra predominante após o desmatamento é a pastagem, que também emprega poucas pessoas. Onde o cultivo mecanizado de arroz e soja é lucrativo, estes usos estão presentes em áreas crescentes. Esta forma de agricultura substitui a mão-de-obra braçal pela maquinaria e os herbicidas. Entre os fatores que desencorajam usos da terra que empregariam mais pessoas em áreas desmatadas está o medo de que meeiros e/ou trabalhadores contratados ganhem direitos de posse sobre a terra que eles cultivam. Estratégias para evitar tais reivindicações de posse pela terra incluem a atual combinação de usos da terra que exigem pouca mão-de-obra e a periódica expulsão e substituição de trabalhadores e arrendatários.

O Brasil precisa enfrentar urgentemente o desafio de fazer a transição em deixar de usar o costume de direitos de posse como uma válvula de escape para desigualdades e injustiças de todos os tipos, assim como também por fim ao padrão de permitir e legitimar apropriação de grandes áreas de terra pública por grileiros. Mais cedo ou mais tarde, este costume fatalmente vai mudar, na medida em que chegam ao limite as áreas de floresta disponíveis. Os benefícios ambientais e sociais seriam grandes se a transição pudesse ser alcançada logo, bem antes que o País seja forçado a isto por falta de floresta adicional para invadir. Infelizmente, a "MP da grilagem” (Medida Provisória 458/2009), já aprovada pelo Congresso Nacional, representa um grave retrocesso neste sentido, legalizando uma grande área de ocupações ilegais passadas e criando a expectativa geral de que, no futuro, os que seguem invadindo também serão beneficiados.

Na maioria das partes do mundo esta transição já foi feita há muito tempo: pessoas desempregadas que faltam os recursos para começar um negócio próprio enfrentam a opção de buscar alguma forma de emprego, urbano ou rural. Nem ia passar pela cabeça de tais pessoas a idéia de que elas teriam um direito inato de invadir qualquer terra "não utilizada", tal como terra pública na Amazônia, para começar uma propriedade nova. É claro que, em alguma época no passado distante, os antepassados de praticamente todas as pessoas de hoje reivindicaram terra por 
meio de simples ocupação. No Brasil esta forma de transferir terra pública para o domínio privado persiste até os dias de hoje. Abandonar esta tradição requer uma mudança na mente da população. É importante entender que tal mudança de atitude pode acontecer: a tradição de ganhar a posse da terra através da ocupação não é uma parte fixa da paisagem. Um exemplo é fornecido pelo assentamento da parte ocidental dos Estados Unidos, cujo “fechamento da fronteira” em 1890 marcou o fim desta forma de assentamento independente (TURNER, 1893). Para este tipo de mudança acontecer no Brasil por algum meio diferente do simples esgotamento de área de terra, precisa-se de algum marco visível. Se a vontade política para uma mudança desse tipo vier ocorrer as rodovias BR-163 e BR-319 poderiam ser o momento decisivo para o Brasil.

\section{V) O EIA-RIMA DA RODOVIA BR-319}

O EIA-RIMA para a rodovia BR-319 (Manaus-Porto Velho) trata de uma das decisões mais importantes diante o governo brasileiro hoje: se deveria abrir a parte central e norte da Amazônia à migração oriunda do notório "arco de desmatamento", que atualmente se restringe ao sul da Amazônia. A proposta reabertura da rodovia BR-319, uma estrada abandonada há mais de 20 anos, facilitaria em muito o movimento de atores do arco de desmatamento, inclusive grileiros (apropriadores ilegais de grandes áreas de terra pública) e de sem terras (grupos organizados de camponeses pequenos que não possuem terras) (FEARNSIDE \& GRAÇA, 2006; FEARNSIDE, 2008). A região de Manaus, por exemplo, tem sido poupada de conflitos agrários resultantes da busca por terra, tais como a invasão de fazendas por sem terras, e o ciclo resultante de desmatamento onde os posseiros desmatam para estabelecer as suas reivindicações e os grandes proprietários de terras desmatam para evitar que as terras sejam invadidas ou então confiscadas pelo governo para fins de reforma agrária. A situação inusitada na Amazônia central somente é possível por causa da dificuldade de chegar até esta área na ausência de uma conexão por estrada. O EIA-RIMA especificamente rejeita um aumento da migração como impacto da BR-319, declarando que " $A$ existência de uma migração reprimida é um fenômeno questionável, já que, desde os tempos da colonização da Amazônia, o uso da via fluvial tem sido intenso, sendo o principal meio de acesso às diversas cidades da região” (UFAM, 2009a, Vol. 1, pág. 189). Infelizmente, a migração tem sido uma ocorrência repetida quando outras áreas foram abertas por estradas, como foi o caso da BR-364 em Rondônia (por exemplo, FEARNSIDE, 1986b).

O EIA-RIMA contém a confissão extraordinária de que a BR-319 tem “baixa importância para o Pólo Industrial de Manaus” (UFAM, 2009a, Vol. 1, pág. 
216). Seguramente, isto deve ser uma das declarações mais extraordinárias nos 23 anos de história do EIA-RIMA no Brasil. A importância alegada da BR-319 para o Pólo Industrial de Manaus sempre foi a principal justificativa para a existência da rodovia. Infelizmente, a afirmação da inexistência de interesse é completamente verdadeira, e isto foi declarado publicamente pelo representante da Federação das Indústrias do Amazonas (FIAM) no evento realizado na Superintendência da Zona Franca de Manaus (SUFRAMA) em 19 de março de 2008. O referido evento teve por objetivo debater a proposta, que estava sendo apoiada pelo governo do Estado do Amazonas naquele momento, para substituir o projeto da rodovia BR-319 por uma ferrovia. Ampla informação existe mostrando que a cabotagem em navios oceânicos de Manaus para Santos é um meio muito mais barato para transportar a produção das fábricas em Manaus para São Paulo do que transporte por qualquer rota rodoviária (FEARNSIDE \& GRAÇA, 2006, 2009; PEIXOTO, 2006; TEIXEIRA, 2007). Por exemplo, Teixeira (2007), investigando as opções de transporte de carga geral nas conexões com a região amazônica, concluiu que o transporte marítimo por cabotagem reduz os custos do transporte na ligação Manaus-São Paulo em 37\%, quando comparado com os atuais meios de transporte. Por sua vez, a mesma autora, quando considera a construção da rodovia (BR-319) ligando ao resto da malha rodoviária brasileira, os custos aumentam em 19\% em relação à rota atual, que utiliza a hidrovia até Belém.

O EIA-RIMA calcula o benefício da rodovia como a receita bruta do frete e do tráfego de passageiros que os autores esperam passar pela rota. Esta receita, é claro, não constitui nenhum tipo de benefício, mas sim um custo a ser pago por aqueles que usam a rodovia. Por esta lógica, quanto mais ineficiente e mais caro o transporte, maior o "benefício" que poderia ser contabilizado (L. FLECK, declaração pública, 15 de abril de 2009)! O benefício deveria ser calculado como a diferença entre o custo de transporte entre Manaus e São Paulo pela rodovia e o custo de transporte pela alternativa mais barata. Neste caso, a alternativa mais barata para a maioria do frete seria transporte em contêineres por cabotagem, e o "benefício" seria negativo porque a alternativa é mais barata que a rodovia. Observa-se que a viagem que precisa ser comparada para a maior parte do cálculo está entre Manaus e São Paulo, não entre Manaus e Porto Velho (UFAM, 2009a, Vol.1, item Análise Financeira do Projeto, pág. 191). Porto Velho serve apenas como um entreposto para os caminhoneiros em trânsito para São Paulo, e não como o destino final do transporte.

A quantidade de tráfego que os autores do EIA-RIMA esperam está baseada em suposições extraordinariamente otimistas. Eles esperam 375.000 passageiros de ônibus por ano a partir de 2012, data esperada de inauguração 
da rodovia (UFAM, 2009a, Vol. 1, pág. 193), o que é aproximadamente igual à população inteira da cidade de Porto Velho, que era de 368.345 habitantes em 2007 (UFAM, 2009a, Vol. 4, pág. 25). Vale à pena lembrar que atualmente o número de imigrantes chegando a Manaus é 1,8 vezes maior que o número de emigrantes saindo da cidade (UFAM, 2009a, Vol. 4, p. 208), e que a proporção de viagens no sentido Porto Velho-Manaus deve guardar uma proporção similar em comparação às viagens Manaus-Porto Velho depois de abrir a estrada. Esta migração líquida de desempregados para Manaus não representaria um benefício para Manaus de hipótese alguma, mas sim um custo enorme em termos de gastos municipais com serviços e em termos de outros impactos sociais.

Os autores do EIA declaram: "a rodovia BR-319 é encarada como uma promissora rota de exportação de commodities do agronegócio (soja e álcool)" (UFAM, 2009a, Vol. 1, p. 184). Porém, é improvável que este tipo de frete seja transportado por estrada, uma vez que estes produtos são muito mais baratos transportados a granel, em barcaças, do que fracionar o frete em contêineres ou caminhões. Poupar alguns poucos dias em transporte não justifica o custo substancialmente mais alto de transportar este tipo de frete por caminhão. A literatura de transporte trata a "carga geral" (carga fracionada) de uma maneira completamente diferente do transporte a granel (p. exemplo, cereais, carvão, minerais, etc.), devido aos custos muito discrepantes associados ao transporte, carregamento e administração destas duas classes distintas de frete. O EIA simplesmente usa uma equivalência de $60 \mathrm{t}$ de grãos como igual a um contêiner (UFAM, 2009a, Vol. 1, pág. 192).

As quantidades de produtos agrícolas que o EIA-RIMA espera que sejam transportadas para Manaus estão baseado na suposição de que $20 \%$ do potencial agrícola de Rondônia e de uma grande área em Mato Grosso serão transportados para Manaus pela rodovia. Nenhuma relação com a demanda em Manaus é demonstrada. A produção na área da qual os produtos agrícolas são obtidos totalizou 28 milhões de toneladas em 2006 (UFAM, 2009a, Vol. 1, pág. 192). Isto é composto de $49,2 \%$ soja, $16,0 \%$ madeira, $15,9 \%$ milho, $15,9 \%$ lenha, $2,5 \%$ culturas permanentes, $0,3 \%$ álcool e 0,2\% açúcar (UFAM, 2009a, Vol. 1, pág. 185).

Um dos aspectos mais notáveis do EIA-RIMA é a seletividade com que são comparados os impactos e os benefícios. A abrangência máxima dos impactos está limitada à "área de influência indireta” ao longo da rota da rodovia, abarcando a faixa entre os rios Madeira e Purus (UFAM, 2009b, págs. 12-13), enquanto os benefícios são reivindicados para uma área muito maior, inclusive a cidade de Manaus, áreas agrícolas em Mato Grosso, e até mesmo outros países conectados à rede rodoviária pela infra-estrutura planejada sob a IIRSA (Iniciativa para 
Infra-Estrutura da América do Sul) (UFAM, 2009a, Vol. 1, pág. 158). A “área de influência" para passageiros inclui uma população de 6,4 milhões que engloba Manaus, Rondônia e grande parte de Mato Grosso (UFAM, 2009a, Vol. 1, pág. 193). Impactos ao norte do rio Amazonas, incluindo os na cidade de Manaus, no Distrito Agropecuário da SUFRAMA ao norte de Manaus que provavelmente será invadido por sem terras, e no Estado de Roraima e outras áreas para as quais acesso rodoviário de Manaus já existe, não são mencionados. Também não são consideradas as estradas prováveis a serem construídas para ligar a BR-319 à área de floresta intacta ao oeste do Rio Purus (Figura 4).

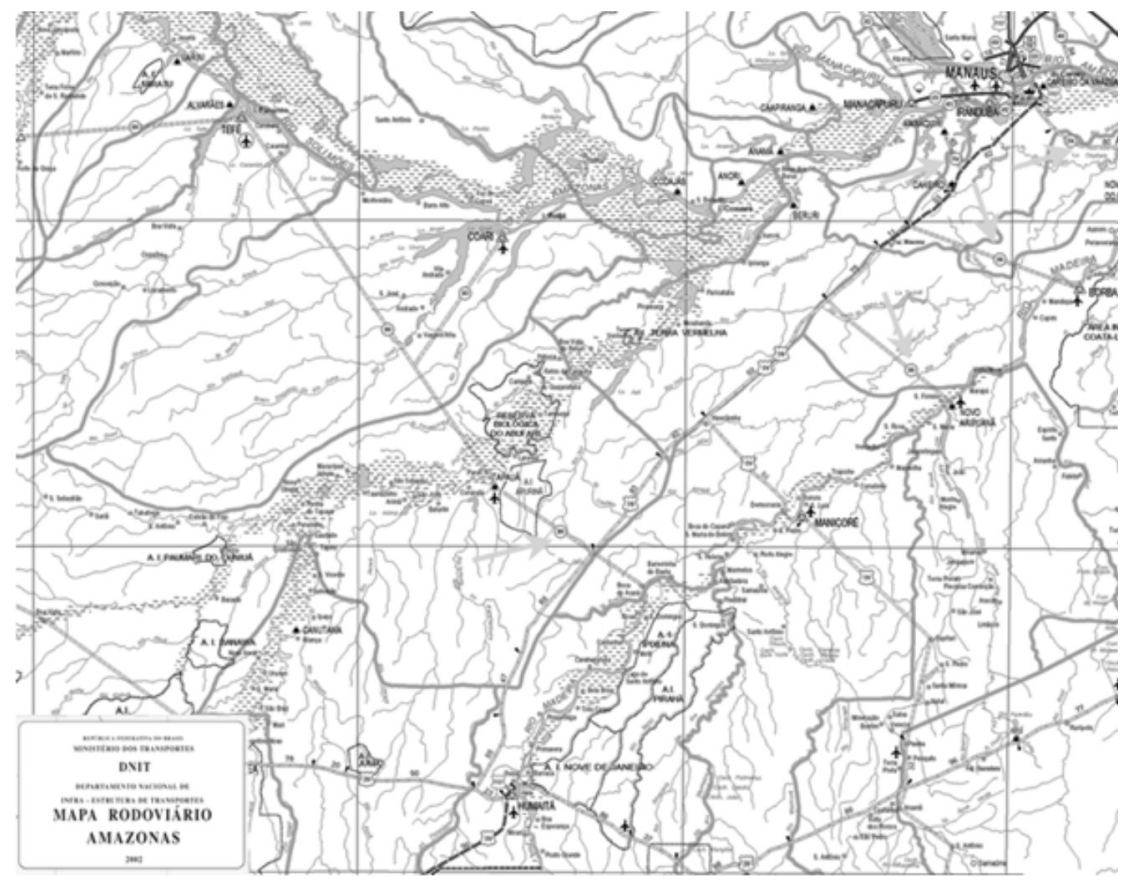

Figura 4. Mapa rodoviário do Amazonas incluindo estradas planejadas ao longo da BR 319 (indicadas por setas amarelas).

Fonte: (Brasil, DNIT, 2002, acrescentadas as setas).

O EIA especificamente exclui a consideração dessas estradas planejadas, observando "É interessante notar que a rodovia AM-366 faz parte de um planejamento de expansão rodoviária antigo. Segundo o planejado, esta rodovia seguiria em direção oeste, atravessando o rio Purus em direção à sede do município de Tefé, bifurcando-se na altura do rio Coari em direção a cidade de Coari e, a partir de Tefé, indo até o rio Juruá. Antes disso, apresentaria ainda uma ligação com a sede do município de Beruri. Segundo o planejado, esta rodovia seguirá, embora este planejamento faça parte do mapa oficial do planejamento 
do Ministério dos Transportes. A exceção da rodovia BR-319, nenbuma dessas estradas está no planejamento do Governo Federal" (UFAM, 2009b, Vol. 1, p. 58). No entanto, estas estradas adicionais, que se ramificam a partir da BR-319, fazem parte dos planos oficiais do Departamento Nacional de Infraestrutura de Transportes (DNIT) e continuam sendo exibidas no site da internet do DNIT até hoje (BRASIL, DNIT, 2002).

O fator chave na conclusão dos autores do EIA-RIMA sobre a viabilidade ambiental da obra é a sua crença em um cenário de "forte governança ambiental." Eles concluem "quando se coteja com o cenário de governança ambiental forte, todos os indicadores (VPL [valor liquido presente], TIR [taxa interna de retorno] e IBC [indice custo/benefício]) se mostram altamente favoráveis ao projeto. Nesse cenário, os custos ambientais são mitigados a um nível desejável que torna o projeto socialmente desejável" UFAM, 2009a,Vol. 1, págs. 202-203). O exemplo dado desta "forte governança ambiental" é: "Não necessariamente o fato de ter rodovias em áreas de concentração de recursos naturais implica em degradação do patrimônio natural. Um exemplo de turismo sustentável é aquele realizado no Parque Nacional de Yellowstone" (UFAM, 2009a, Vol. 1, pág. 204). Isto é seguido pelo mapa do parque de Yellowstone, indicando as estradas existentes dentro do parque, onde, é claro, ninguém desmata nada (Figura 5). Por coincidência, um de nós (PMF) é um ex-funcionário do Serviço de Parques Nacionais, dos EUA, e trabalhou como naturalista em um parque não muito distante de Yellowstone. A noção de que um cenário similar ao parque de Yellowstone se instalará na área aberta pela BR-319 é totalmente fora da realidade na área atualmente, onde há um cenário típico do "arco do desmatamento" ao seu redor, caracterizado pela disputa por terras e todos os seus desdobramentos (grileiros, posseiros, madeireiros ilegais). Parece mais realista que após o tempo que levaria para o cenário atual evoluir para o de Yellowstone, já não teria praticamente mais floresta na área! Presumir que um cenário tão fora da realidade atual se instala com a rapidez necessária para evitar graves impactos ambientais é extremamente perigoso como presunção para embasar decisões como a da abertura da estrada.

A falta de uma justificativa econômica se torna até irônica com a argumentação de que "Cada vez mais a sociedade brasileira questiona a elevada carga tributária, que atualmente está em torno de $37 \%$ do PIB. Portanto, é importante a aplicação eficiente dos recursos públicos na forma de projetos que atendam ao interesse da sociedade" (UFAM, 2009a, Vol. 1, pág. 177). Evidentemente, concordamos com a importância de não desperdiçar o dinheiro do contribuinte, o que deve ser um forte argumento contra a realização desta obra. Os autores do EIA-RIMA até sugeriram repassar parte do ônus mal contabilizado desta obra para os usuários, 
por meio da cobrança de um novo tipo de imposto na forma de um "pedágio ambiental” (UFAM, 2009a, Vol. 1, págs. 211-212).

\section{(7) DNIT}

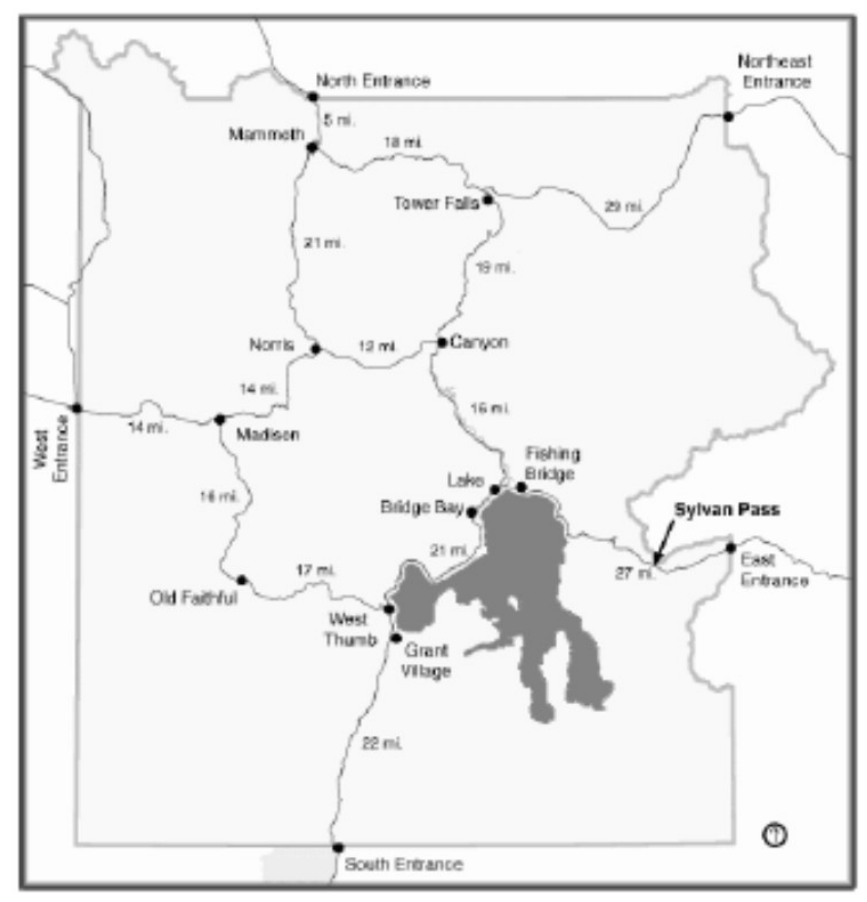

Figura 5. Mapa do Parque Nacional de Yellowstone, nos EUA, dado como exemplo de "governança ambiental forte" no EIA-RIMA.

Fonte: UFAM, 2009a,Vol. 1, pág. 205).

A análise de custos ambientais realizada pelo EIA, considerou quatro cenários (um sem governança e os demais com governança fraca, moderada e forte) para a mensuração dos custos ambientais da pavimentação da rodovia BR319. Nesta análise os autores concluíram que devido aos altos custos ambientais a reconstrução da rodovia só teria viabilidade econômica no caso de um cenário de governança ambiental (UFAM, 2009a, Vol.1, pág. 203). No entanto, os custos ambientais para a realização de uma governança ambiental, tais como a implementação de Unidades de Conservação, postos de fiscalização, contratação de pessoal, não foram considerados na análise de custos. De acordo com dados preliminares de um estudo realizado pela Conservação Estratégica (CSF-Brasil), em abril de 2009, a implantação de 29 parques e reservas ao longo da rodovia gerará 
um custo estimado de $\mathrm{R} \$ 578$ milhões, que não será coberto pela economia nos transportes. O custo para a implementação dessas áreas de proteção ambiental atualmente pelo governo é estimado em apenas 39 milhões de reais (BRASIL, MINISTÉRIO DOS TRANSPORTES, 2009, pág. 5). Apesar da "blindagem verde" proposta para a BR 319, é possível que grandes áreas de florestas remotas bem conservadas sejam atingidas pelo desmatamento caso as estradas laterais planejadas pelo DNIT venham a ser realizadas. Por exemplo, já existe a um trecho aberto da extensão BR-174, que liga a BR-319 a Manicoré, atualmente intransitável, que ultrapassa essa "blindagem verde". Pior, a estrada planejada cruzando o rio Purus em Tapauá abriria uma vasta área para desmatamento atrás da estreita fila proposta ao lado da rodovia BR-319.

Nenhum estudo de viabilidade existe para a BR-319. Um estudo de viabilidade consiste em uma estimativa detalhada dos custos e benefícios financeiros de um projeto proposto. Obviamente, este é um elemento fundamental no processo de tomada de decisão para qualquer projeto de infra-estrutura. No caso da rodovia BR-319, o Ministério dos Transportes argumentou que nenhum estudo de viabilidade é preciso, pois considera que este projeto é apenas uma "recuperação" de uma estrada existente. $\mathrm{O}$ mesmo argumento era usado pelo Ministério dos Transportes ao reivindicar que nenhum EIA-RIMA seria necessário, mas isto não foi aceito pelos tribunais e agora foi elaborado um EIA-RIMA. A pergunta de por que um estudo de viabilidade também não foi realizado permanece. Por exemplo, a rodovia BR-163 (Santarém-Cuiabá), que também é um projeto de "reconstrução" de rodovia, tem os dois tipos de relatório: o EIA-RIMA e o estudo de viabilidade.

Qualquer tomada de decisão racional sobre projetos de infra-estrutura como a rodovia BR-319 deve pesar todos os custos e benefícios para todas as alternativas, inclusive a opção sem o projeto, antes que uma decisão fosse tomada. A finalidade de avaliações ambientais é de prover informações para tomar uma decisão racional. Neste caso, a consideração dos custos e benefícios é altamente seletiva, omitindo as comparações econômicas principais que precisam ser feitas relativo ao transporte entre Manaus e São Paulo (não somente entre Manaus e Porto Velho), e omitindo os impactos ambientais principais que seriam o resultado da migração para áreas fora da área ao longo da extensão de rodovia planejada para reconstrução. A apresentação das informações no EIA-RIMA deve ser de uma forma objetiva para permitir uma decisão livre sobre a obra pela sociedade e pelas autoridades competentes. Os autores do RIMA não demonstram nenhuma preocupação em manter uma posição neutra sobre a obra, concluindo que: " $A O$ final, reiteramos a relevância desta obra como instrumento de integração dos 
estados do Amazonas e Roraima ao restante do país e a importância de que ela seja executada com base em alicerces econômicos, sociais e ecológicos fortes e equilibrados" (UFAM, 2009b, pág. 38).

\section{VI) CONCLUSÕES}

O custo ambiental não contabilizado de conectar a Amazônia Central com o "Arco de Desmatamento" precisa ser incorporado no processo de decisão antes dela ser tomada sobre a reconstrução e pavimentação da rodovia BR-319. Embora seja lógico, em uma escala de tempo de décadas, esperar que a pavimentação desta rodovia se concretize, o custo ambiental seria alto se isto for realizado sem primeiro preparar as áreas para as quais os impactos potenciais estendem, inclusive Roraima. Estas preparações incluem zoneamento ecológico-econômico, estabelecimento de reservas, e aumento do nível de governança, a ponto que o impacto de um fluxo crescente de migrantes poderia ser contido. Mais fundamentalmente, o Brasil precisa passar por uma transição de modo que a tradição secular de conceder a posse da terra a migrantes que invadem áreas de floresta seja encerrada. Isto significa prover uma válvula de escape para muitos problemas do País que não podem ser sustentados, e é melhor substituir isto com oportunidades de emprego melhores em áreas urbanas e rurais antes que esta transição no País seja forçada pela dizimação da floresta.

\section{VII) AGRADECIMENTOS}

Ao Conselho Nacional do Desenvolvimento Científico e Tecnológico (CNPq: Proc. 470765/01-1) e o Instituto Nacional de Pesquisas da Amazônia (INPA: PPI 1-1005) por fornecer apoio financeiro. E.M. Nogueira ajudou no trabalho de campo e R.I. Barbosa contribuiu com valiosos comentários. Agradecemos aos colonos e outros ao longo da BR-319 pela paciência e cooperação. Parte deste trabalho é atualizada de uma tradução de Fearnside \& Graça (2006) e de uma contribuição à globoamazonia.com (FEARNSIDE \& GRAÇA, 2009).

\section{REFERÊNCIAS}

ABDALA, I. "Governo retoma o projeto do asfalto da Manaus-Caracaraí." Amazonas em Tempo [Manaus] 29 de janeiro de 1996. p. 8, 1996.

ALMEIDA, P. "Empresários defendem a BR-319." Amazonas em Tempo [Manaus] 29 de março de 2005. p. B-6, 2005.

AMAZONAS EM TEMPO. "PL denuncia lobby contra a recuperação da BR- 
319”. Amazonas em Tempo [Manaus]. 10 de março de 2005, p. A-1, 2005a.

AMAZONAS EM TEMPO. "Rodovia BR-319 será o corredor de agricultura familiar". Amazonas em Tempo [Manaus]. 05 de junho de 2005, p. A-5, 2005b.

AMAZONAS EM TEMPO. "Demarcação de terras em Tapauá gera polêmica". Amazonas em Tempo [Manaus]. 17 de junho de 2005, p. B-7, 2005c.

BANEGA, A.; GOMES, K. "BR-319 começa a ser recuperada". Amazonas em Tempo [Manaus]. 09 de julho de 2005, p. A-5, 2005.

BANEGA, A.; SIMONETTI, A. "Alfredo garante: Enfim, a BR-319 será recuperada." Amazonas em Tempo [Manaus]. 06 de março de 2005, p. B-4, 2005.

BARNI, P. E.; FEARNSIDE, P. M.; GRAÇA, P. M. L. A. Deforestation and carbon emissions in Amazonia: Simulating the impact of connecting Brazil's state of Roraima to the "arc of deforestation" by reconstructing the BR-319 (ManausPorto Velho) Highway. In: WILLIAMS, C. (ed.). XIII World Forestry Congress, Buenos Aires, Roma, Itália: Food and Agriculture Organization of the United Nations (FAO). (no prelo), 2009.

BRASIL, BNDES. Transporte na Região Amazônica. Cadernos de InfraEstrutura No. 7, Rio de Janeiro, RJ: BNDES. 114p., 1998. http://www.finame. com.br/conhecimento/cadernos/aicad_07.pdf.

BRASIL, DNIT. Mapa Rodoviário Amazonas. Escala: 1:2.250.000. Brasília, DF: Departamento Nacional de Infraestrutura de Transportes (DNIT), Ministério dos Transportes, 2002. Disponível em: http://www.dnit.gov.br/menu/rodovias/mapas BRASIL, IBGE, IBGE. Rio de Janerio, RJ: Instituto Brasileiro de Geografia e Estatística (IBGE), 2005. http:/ /www.ibge.gov.br

BRASIL, MINISTÉRIO DE PLANEJAMENTO, ORÇAMENTO E GESTÃO (MPOG). PPA 2004-2007. Lista Geral de Projetos de Infra-estrutura. Setembro 2004. Brasília, DF: MPOG, 2004. http://www.planobrasil.gov.br/arquivos/57_ (LivroVermelhonov2004).pdf

BRASIL, MINISTÉRIO DOS TRANSPORTES. BR-319: A rodovia parque. 15 p., 2009.

BRASIL, PIN (Programa de Integração Nacional). Colonização da Amazônia. Brasília, DF: PIN, 32 p., 1972.

BRASIL, PROGRAMA AVANÇA BRASIL. PPA Plano Plurianual 2000-2003. Brasilia, DF: Ministério de Planejamento, 1999. http:/ /www.abrasil.gov.br.

BRASIL, PROGRAMA BRASIL EM AÇÃO. Brasília, DF: Brasil em Ação, 1999. http://www.brazil-in-action.gov.br. (site não mais disponível). 
BRASIL, PROJETO RADAMBRASIL. Levantamento de Recursos Naturais. Rio de Janeiro, RJ: Ministério das Minas e Energia, Departamento de Produção Mineral (DNPM), 27 Vols., 1973-1982.

BRASIL, SUFRAMA. Indicadores de desempenho do pólo industrial de Manaus. Manaus, Amazonas: Superintendência da Zona Franca de Manaus (SUFRAMA), 2005a. http://www.suframa.gov.br/download/indicadores/indica_abril05.htm

BRASIL, SUFRAMA. Pólo industrial de Manaus. Manaus, Amazonas: Superintendência da Zona Franca de Manaus (SUFRAMA). Apresentação Powerpoint, 2005b.

BROWDER, J. O.; GODFREY, B. J. Rainforest Cities: Urbanization, Development and Globalization of the Brazilian Amazon. New York, NY, E.U.A.: Columbia University Press, 427 p., 1997.

CNT. Transporte de Cargas no Brasil: Ameaças e Oportunidades para o Desenvolvimento do País. Diagnóstico e Plano de Ação. Rio de Janeiro, RJ: Confederação Nacional do Transporte (CNT) \& Centro de Estudos em Logística (COPPEAD), Universidade Federal do Rio de Janeiro (UFRJ), 200p., 2002. http:// www.coppead.ufrj.br/pesquisa/cel/ new/pesq-trans/DIAGNOSTICO_e_ PLANO_DE_ACAO.pdf

CONSÓRCIO BRASILIANA. Programa Brasil em Ação: Eixos Nacionais de Integração e Desenvolvimento. Banco Nacional de Desenvolvimento Econômico e Social (BNDES) PBA/CN-01/97. Relatório Final do Marco InicialBrasilia, DF:, Consórcio Brasiliana, 3 vols., 1998.

ESTADO DO AMAZONAS. Zoneamento Ecológico-Econômico no Estado do Amazonas. Junho de 2001. Diretrizes Iniciais para um Ordenamento Ecológico-Econômico do Sudeste-Sul do Estado do Amazonas. Manaus, Amazonas: Instituto de Proteção Ambiental do Amazonas (IPAAM), 2001.

FEARNSIDE, P. M. Agriculture in Amazonia. p. 393-418 In: PRANCE, G.T.; LOVEJOY, T.E. (eds.). Key Environments: Amazonia. Oxford, Reino Unido: Pergamon Press, 442 p., 1985.

FEARNSIDE, P. M. Settlement in Rondônia and the token role of science and technology in Brazil's Amazonian development planning. Interciencia 11(5): 229-236, 1986a.

FEARNSIDE, P. M. Spatial concentration of deforestation in the Brazilian Amazon. Ambio 15(2): 72-79, 1986b.

FEARNSIDE, P. M. Deforestation and international economic development projects in Brazilian Amazonia. Conservation Biology 1(3): 214-221, 1987.

FEARNSIDE, P. M. Brazil's Balbina Dam: Environment versus the legacy of the 
pharaohs in Amazonia. Environmental Management 13(4): 401-423, 1989a. FEARNSIDE, P. M. Ocupação Humana de Rondônia: Impactos, Limites e Planejamento. Relatórios de Pesquisa No. 5,: Brasília, DF: Conselho Nacional de Desenvolvimento Científico e Tecnológico (CNPq). 76 p., $1989 \mathrm{~b}$.

FEARNSIDE, P. M. Land-tenure issues as factors in environmental destruction in Brazilian Amazonia: The case of southern Pará. World Development 29(8): 1361-1372, 2001.

FEARNSIDE, P. M. Avança Brasil: Environmental and social consequences of Brazil's planned infrastructure in Amazonia. Environmental Management 30: 748-763, 2002.

FEARNSIDE, P. M. Deforestation control in Mato Grosso: A new model for slowing the loss of Brazil's Amazon forest. Ambio 32(5): 343-345, 2003.

FEARNSIDE, P. M. Carga pesada: O custo ambiental de asfaltar um corredor de soja na Amazônia. In: TORRES, M. (ed.) Amazônia revelada: os descaminhos ao longo da BR-163. Brasília, DF: Conselho Nacional de Desenvolvimento Científico e Tecnológico (CNPq), 2005.

FEARNSIDE, P. M. The roles and movements of actors in the deforestation of Brazilian Amazonia. Ecology and Society 13(1): 23. [online], 2008. URL: http://www.ecologyandsociety.org/vol13/iss1/art23/

FEARNSIDE, P. M.; BARBOSA, R. I. Political benefits as barriers to assessment of environmental costs in Brazil's Amazonian development planning: The example of the Jatapu Dam in Roraima. Environmental Management 20(5): 615-630, 1996a.

FEARNSIDE, P. M.; BARBOSA, R. I. The Cotingo Dam as a test of Brazil's system for evaluating proposed developments in Amazonia. Environmental Management 20(5): 631-648, $1996 \mathrm{~b}$.

FEARNSIDE, P. M.; BARBOSA, R. I. Avoided deforestation in Amazonia as a global warming mitigation measure: The case of Mato Grosso. World Resource Review 15(3): 352-361, 2003.

FEARNSIDE, P. M.; GRAÇA, P. M. L. A. BR-319: Brazil's Manaus-Porto Velho Highway and the potential impact of linking the arc of deforestation to central Amazonia. Environmental Management 38(5): 705-716, 2006.

FEARNSIDE, P. M.; GRAÇA, P. M. L. A. Transporte hidroviário por cabotagem como alternativa à Rodovia Manaus-Porto Velho (BR-319). p. 437-441 In: MACHADO, J. A. C. (ed.). Anais da IV Jornada de Seminários Internacionais sobre Desenvolvimento Amazônico, Volume 3. Manaus, Amazonas: Superintendência da Zona Franca de Manaus (SUFRAMA). 629p., 2009. 
FEARNSIDE, P. M.; GRAÇA, P. M. L. A.; KEIZER, E. W. H.; MALDONADO, F. D.; BARBOSA, R. I.; NOGUEIRA, E. M. Modelagem de desmatamento e emissões de gases de efeito estufa na região sob influência da Rodovia ManausPorto Velho (BR-319). Revista Brasileira de Meteorologia 24(2): 208-233, 2009.

FERREIRA, L. V.; VENTICINQUE, E.; de ALMEIDA, S. S. O Desmatamento na Amazônia e a importância das áreas protegidas. Estudos Avançados 19(53): 1-10, 2005.

FOLHA DE SÃO PAULO. "Em Sorriso, estrada divide Daslu e miséria”. Folha de São Paulo. 19 de junho de 2005, p. B-.4, 2005.

IPIB, IPIB - Internet Produto Interno Bruto. Rio de Janerio, RJ, 2005. http:// www.ipib.com.br

LAURANCE, W. F; ALBERNAZ, A. K. M.; SCHROTH, G.; FEARNSIDE, P. M.; BERGEN, S.; VENTINCINQUE, E. M.; da COSTA, C. Predictors of deforestation in the Brazilian Amazon. Journal of Biogeography 29: 737-748, 2002.

LAURANCE, W. F.; COCHRANE, M. A.; BERGEN, S.; FEARNSIDE, P. M.; DELAMÔNICA, P.; BARBER, C.; D'ANGELO, S.; FERNANDES, T. The future of the Brazilian Amazon. Science 291: 438-439, 2001.

LITAIFF, P. 2005. "Grilagem: Balas protegem as terras. Terras ocupadas por grileiros nos municípios do Sul do Amazonas são protegidas à bala por pistoleiros.” Amazonas em Tempo [Manaus]. 04 de junho de 2005, p. B-7.

MAHAR, D. J. Fiscal incentives for regional development: A case study of the western Amazon Basin. Journal of Interamerican Studies and World Affairs 18(3): 357-378, 1976.

NEPSTAD, D. C.; CAPOBIANCO, J. P.; BARROS, A. C.; CARVALHO, G.; MOUTINHO, P.; LOPES, U.; LEFEBVRE, P. Avança Brasil: Os custos ambientais para Amazônia. Belém, Pará: Instituto de Pesquisa Ambiental da Amazônia-IPAM, 24p., 2000. (disponível em: http://www.ipam.org.br/avanca/politicas.htm).

NEPSTAD, D. C.; CARvalho, G.; BARros, A. C.; AlEnCAR, A. A.; CAPOBIANCO, J. P.; BISHOP, J.; MOUTINHO, P.; LEFEBVRE, P.; SILVA JR., U. L.; PRINS, E. 2001. Road paving, fire regime feedbacks, and the future of Amazon forests. Forest Ecology and Management 154(3): 395-407.

ONO, R.T. Estudo de Viabilidade do Transporte Marítimo de Conteiners por Cabotagem na Costa Brasileira. Dissertação de mestrado em engenharia, Escola Politêcnica da Universidade de São Paulo (USP), São Paulo, SP: USP. 136p., 2001. http://www.teses.usp.br/teses/disponiveis/ 3/3135/tde-16012002-102949/ publico/teses_online.pdf 
PEIXOTO, T.F.A. Quadro comparativo entre as diferentes modalidades de transporte de mercadorias. p. 89-108 In: FREITAS, A.; PORTUGUAL, L.S. (eds.). Estudos de Transporte e Logística na Amazônia. Manaus, Amazonas: Novo Tempo, 396p., 2006.

SCHNEIDER, R. R.; ARIMA, E.; VERÍSSIMO, A.; BARRETO, P.; SOUZA JUNIOR, C. Amazônia Sustentável: Limitantes e Oportunidades para o Desenvolvimento Rural, Brasília, DF: World Bank \& Belém, Pará: Instituto do Homem e Meio Ambiente da Amazônia (IMAZON). 58p., 2000.

SIMONETTI, A. "BR-163: Preservação em primeiro lugar. A secretária de Coordenação da Amazônia do Ministério do Meio Ambiente, Muriel Saragoussi, garante que a recuperação da rodovia BR-163 vai beneficiar a Zona Franca." Amazonas em Tempo [Manaus] 01 de abril de 2005. p. A-3, 2005.

SOARES-FILHO, B.S. SIMAMAZONIA. Centro de Sensoriamento Remoto (CSR), Belo Horizonte, Minas Gerais: Universidade Federal de Minas Gerais (UFMG), 2004. http://www.csr.ufmg.br/simamazonia

TEIXEIRA, K.M. Investigação de Opções de Transporte de Carga Geral em Conteineres nas Conexões com a Região Amazônica. Tese de doutorado em Engenharia de Transportes, Universidade de São Paulo (USP), Escola de Engenharia de São Carlos, São Carlos, São Paulo: USP. 235p., 2007.

TURNER, F.J. The Significance of the Frontier in American History, Proceedings of the American Historical Association for 1893, p. 199-222. Reeditado em forma expandida: The Frontier in American History. Mineola, NY, E.U.A.: Dover Publications, 384p., 1893. (republicado 1996).

UFAM. Estudo de Impacto Ambiental - EIA: Obras de reconstrução/ pavimentação da rodovia BR-319/AM, no segmento entre os $\mathrm{km} 250,0$ e km 655,7. Dover Publications, Manaus, Amazonas: Dover Publications. 6 Vols. + Anexos, 2009a.

UFAM. Relatório de Impacto Ambiental - RIMA: Obras de reconstrução/ pavimentação da rodovia BR-319/AM, no segmento entre os km 250,0 e km 655,7. Manaus, Amazonas: Universidade Federal do Amazonas (UFAM). 38p., 2009b. 